\title{
Neuronal firing and waveform alterations through ictal recruitment in humans
}

\author{
Edward M. Merricks ${ }^{1}$, Elliot H. Smith ${ }^{1,2}$, Ronald G. Emerson ${ }^{3}$, Lisa M. Bateman ${ }^{1}$, Guy M. McKhann II ${ }^{4}$, \\ Robert R. Goodman ${ }^{5}$, Sameer A. Sheth ${ }^{6}$, Bradley Greger ${ }^{7}$, Paul A. House ${ }^{8}$, Andrew J. Trevelyan ${ }^{9}$, \\ Catherine A. Schevon ${ }^{1 *}$
}

1. Department of Neurology, Columbia University Medical Center, New York NY

2. Department of Neurosurgery, University of Utah, Salt Lake City UT

3. Department of Neurology, Weill Cornell Medical Center, New York, NY

4. Department of Neurosurgery, Columbia University Medical Center, New York NY

5. Department of Neurosurgery, Lenox Hill Hospital, New York NY

6. Department of Neurosurgery, Baylor College of Medicine, Houston TX

7. School of Biology and Health Systems Engineering, Arizona State University, Tempe AZ

8. Intermountain Healthcare, Murray UT

9. Institute of Neuroscience, Newcastle University, Newcastle upon Tyne, UK

* Corresponding author: cas2044@cumc.columbia.edu

Number of figures: 9

Number of tables: 3

Words in abstract: 250

Words in introduction: 446

Words in discussion: 1,499

Funding:

NIH R01 NS084142; CRCNS R01 NS095368

Conflicts of interest:

None. 


\section{AbSTRACT}

2 Clinical analyses of neuronal activity during seizures, invariably using extracellular recordings,

3 is greatly hindered by various phenomena that are well established in animal studies: changes in

4 local ionic concentration, changes in ionic conductance, and intense, hypersynchronous firing.

5 The first two alter the action potential waveform, whereas the third increases the "noise"; all

6 three factors confound attempts to detect and classify single neurons (units). To address these

7 analytical difficulties, we developed a novel template-matching based spike sorting method,

8 which enabled identification of 1,239 single units in 27 patients with intractable focal epilepsy,

9 that were tracked throughout multiple seizures. These new analyses showed continued neuronal

10 firing through the ictal transition, which was defined as a transient period of intense tonic firing

11 consistent with previous descriptions of the ictal wavefront. After the ictal transition, neurons

12 displayed increased spike duration $(p<0.001)$ and reduced spike amplitude $(p<0.001)$, in

13 keeping with prior animal studies; units in non-recruited territories, by contrast, showed more

14 stable waveforms. All units returned to their pre-ictal waveforms after seizure termination.

15 Waveshape changes were stereotyped across seizures within patients. Our analyses of single

16 neuron firing patterns, at the ictal wavefront, showed widespread intense activation, and

17 commonly involving marked waveshape alteration. We conclude that the distinction between

18 tissue that has been recruited to the seizure versus non-recruited territories is evident at the level

19 of single neurons, and that increased waveform duration and decreased waveform amplitude are

20 hallmarks of seizure invasion that could be used as defining characteristics of local recruitment. 


\section{Significance Statement}

23 Animal studies consistently show marked changes in action potential waveform during epileptic

24 discharges, but acquiring similar evidence in humans has proved difficult. Assessing neuronal

25 involvement in ictal events is pivotal to understanding seizure dynamics and in defining clinical

26 localization of epileptic pathology. Using a novel method to track neuronal firing, we analyzed

27 microelectrode array recordings of spontaneously occurring human seizures, and here report two

28 dichotomous activity patterns. In cortex that is recruited to the seizure, neuronal firing rates

29 increase and waveforms become longer in duration and shorter in amplitude, while penumbral

30 tissue shows stable action potentials, in keeping with the "dual territory" model of seizure

31 dynamics. 


\section{2}

33

34

35

\section{Introduction}

A complete understanding of the mechanisms underlying seizure pathology and dynamics depends on knowledge of the local neuronal activity, and what is driving that activity. Comparative animal models have long been used to gain insights into the underlying neuronal activity during seizures (Purpura et al., 1972; Fariello et al., 1976; Grone \& Baraban, 2015), with the paroxysmal depolarizing shift (PDS) being regarded as the intracellular correlate of ictal discharges in animal models for more than half a century (Kandel \& Spencer, 1961a, 1961b; Matsumoto \& Marsan, 1964; Traub \& Wong, 1982).

More recently, early PDSs have been shown to evolve into seizures in vivo (Steriade \& Amzica, 1999), and PDSs have been recorded in resected human cortical tissue (Marcuccilli et al., 2010; Eissa et al., 2016). The PDS causes a decrease in action potential amplitude and an increase in half width - features that should impede standard spike sorting methods - and yet this phenomenon has not been reported in several studies of single unit activity during spontaneous human seizures (Wyler et al., 1982; Babb et al., 1987; Stead et al., 2010; Truccolo et al., 2011, 2014; Bower et al., 2012). In fact, beyond the PDS, altered action potential waveforms could be expected following recruitment of a recording site to a seizure due to alterations to $\mathrm{Na}^{+}$and $\mathrm{K}^{+}$ concentrations in the intracellular and extracellular space or the effects of burst firing (Harris et al., 2000).

We have shown preliminary evidence of such potential alterations (Merricks et al., 2015). In tissue recruited to the seizure, traditional spike sorting methods can fail to cluster single units in human ictal recordings from neocortical layers 4/5, where neuronal cell body density is particularly high (Keller et al., 2018), thereby hindering the ability to track evidence of wave

shape alterations or neuronal firing patterns during and after the ictal wavefront (Merricks et al., 
2015). However, whether this originated from alterations to neurons' intrinsic wave shapes or simply from interference of action potentials from nearby, highly active cells has been unclear.

Here, we present analyses of neuronal activity in the human brain during focal seizures using novel template matching methods in order to characterize action potential waveform

59 alterations and single unit firing patterns, as the ictal wavefront approaches, recruits, and passes

60 the local tissue. We hypothesize that, similar to observations in animal models, human focal

61 seizures consistently display alteration of intrinsic action potential shapes upon ictal recruitment.

62 Specifically, we hypothesize that the distinction between recruited and penumbral tissue is

63 maintained at the level of single neurons, with recruited cells displaying reduced spike amplitude,

64 and increased duration, an effect that is absent in penumbral sites demonstrating increased firing

65 rates, but lacking typical seizure hallmarks.

\section{Materials and Methods}

\section{Human recordings}

Adult patients undergoing surgical evaluation for pharmacoresistant focal epilepsy at

69 Columbia University Irving Medical Center (CUIMC) and University of Utah were implanted 70 with either a 96 channel, 4 x $4 \mathrm{~mm}$ "Utah"-style microelectrode array (UMA; Blackrock

71 Microsystems, Salt Lake City, UT) or Behnke-Fried style microwires (BF array; Ad-tech

72 Medical Equipment Corp, Oak Creek, WI) simultaneous to standard clinical electrocorticography

73 (ECoG) or stereo-electroencephalography (sEEG) respectively. UMAs were implanted into

74 neocortical gyri based on presurgical estimation of the ictogenic region, with electrode tips

75 reaching layer 4/5 (1.0 mm electrode length; layer confirmed via histology in Schevon et al.

76 (2012)), while BF arrays consisted of 8 microwires protruding $\sim 4 \mathrm{~mm}$ from the tips of clinical

77 depth electrodes. 
Neural data were recorded at a sampling rate of $30 \mathrm{kHz}$ on each microelectrode with a range of $\pm 8 \mathrm{mV}$ at 16-bit precision, with a $0.3 \mathrm{~Hz}$ to $7.5 \mathrm{kHz}$ bandpass filter. ECoG and sEEG data were collected with a sampling rate of either $500 \mathrm{~Hz}$ or $2 \mathrm{kHz}$, with 24-bit precision and a

81 bandpass filter of $0.5 \mathrm{~Hz}$ to $1 / 4$ the sampling rate. In UMAs, the reference was either subdural or

82 epidural, chosen based on recording quality. In BF arrays, the reference was the ninth microwire 83 within the bundle.

All procedures were approved by the Institutional Review Boards of CUIMC and University of Utah, and all patients provided informed consent prior to surgery. Clinical determination of seizure onset zone (SOZ) and seizure spread was made by the treating physicians and confirmed prior to analysis by two board-certified neurologists (CAS \& LMB). All analyses were performed offline using custom scripts and toolboxes written in MATLAB (MathWorks, Natick MA). Code is available at https://github.com/edmerix.

The timing of the passage of the ictal wavefront at individual electrodes was calculated

91 based on the MUA firing rate. A Gaussian kernel of 500 ms duration was convolved with the

92 timings of all detected spikes in the MUA, and a sustained, significant increase in the resultant

93 instantaneous firing rate was determined as the moment of local recruitment to the seizure (Smith

94 et al., 2016). A sustained (>1 s), significant increase had to be present for classification as ictal

95 recruitment in order to discount single discharges or herald spikes. Ictal recordings without this

96 signature of tonic to clonic MUA firing were determined to be penumbral. Note that unlike the

97 SOZ, ictal recruitment and the penumbra are spatiotemporally dynamic. As such, a single

98 location, unless at the true origin of the ictal activity, may receive the synaptic input of the

99 upstream ictal activity but remain penumbral due to feed-forward inhibition initially, prior to the

100 transition to the ictal state which may occur at any point during the electroclinical seizure event. 


\section{Peri-ictal single unit discrimination}

Initial spike sorting was performed on the peri-ictal period as per Merricks et al. (2015). order FIR1) to extract multi-unit activity (MUA), from which extracellular action potential spikes were detected using a voltage threshold of $4.5 \sigma$, where $\sigma=\operatorname{median}\left(\frac{|x|}{0.6745}\right)$, and $x$ is the MUA from that channel. This method avoids the biasing effect of large spikes on channels with units with high firing rates (Quian Quiroga et al., 2004). Ictal periods were blanked so that spike sorting was only performed on stable spikes from the peri-ictal period. each detection, and principal component based semi-automatic cluster cutting was performed

111 using a modified version of the "UltraMegaSort2000” MATLAB toolbox (Hill et al., 2011).

112 Artifactually large waveforms were removed by calculating the FFT on spikes up-sampled by a

113 factor of 4, and removing those with power $>5 \mathrm{SD}$ above the mean in frequencies above $2.5 \mathrm{kHz}$

114 or below $500 \mathrm{~Hz}$. Spikes removed in this manner were visually inspected to ensure correct 115 classification as artefact. Clusters that satisfied the following criteria were accepted: (i) clean 116 separation from all other clusters in the Fisher's linear discriminant in principal component 117 space; (ii) less than 1\% contamination of the $2 \mathrm{~ms}$ absolute refractory period; (iii) no clear 118 outliers based on the anticipated chi-squared distribution of Mahalanobis distances; and (iv) less 119 than $1 \%$ of estimated false negatives as estimated by the amount of a Gaussian fit to the detected 120 voltages fell below the threshold for detection, as described in Hill et al. (2011).

\section{Template matching through seizures}

Ictal recruitment has been shown to impede standard spike sorting due to either

123 interference of hypersynchronous activity, intrinsic waveform alterations, or both (Merricks et al.,

124 2015; Fig. 1). We therefore developed novel methods in order to match waveforms from the ictal 
125 period, regardless of recruitment, to their putative neuronal source based on templates derived

126 from the peri-ictal units. In contrast to standard spike sorting methods, these minimized false

127 negatives at the expense of increasing false positives so as to avoid missing potential matches.

128 Cluster boundaries were defined as the 3-dimensional convex hull surrounding the features in

129 principal component space of the previously defined units from both the pre- and post-ictal

130 period (Fig. 2). This method accounts for two situations: that neurons within recruited cortex

131 maintain their wave shape but are obscured by interference from other nearby cells; or that there

132 are occasional or consistent alterations to a neuron's intrinsic waveform that are minor enough to

133 be maintained within the convex hull of feature space. The convex hull allows for alterations to

134 wave shape in any dimension (any direction away from the cluster's centroid).

To avoid ictal results being biased through differing methods, template matching was

136 performed on spikes that were extracted from a period from 10 minutes prior to 10 minutes post

137 seizures, including the ictal activity that had been blanked in the original peri-ictal spike sorting.

138 Channels with unstable units during interictal periods were excluded. Units with no spikes in

139 either the preictal or ictal time period after template matching and artefact removal were

140 excluded from further analyses $(n=77)$.

141 Principal component scores were calculated on these spikes based on the previously

142 defined principal components, and spikes that occurred within a peri-ictal unit's convex hull

143 were assigned to that cell. Mahalanobis distances were calculated for all matches, between their

144 location in principal component space and all peri-ictal waveforms from that unit, on the first $n$

145 principal components that explained $>95 \%$ of the variance in the data set (Fig. 2C). The

146 expected distribution of Mahalanobis distances was calculated as the chi-squared probability

147 distribution with $n$ degrees of freedom. Spikes that had $<0.1 \%$ chance of occurring in the chi148 squared distribution were excluded. 


\section{Spike metrics}

The full-width at half maximum (FWHM) was calculated by up-sampling each spike by a factor of 4 , normalizing the spike voltages to between $[-1,1]$, and finding the difference between the zero-crossings either side of the spike's trough. When calculating spike amplitude changes through the ictal transition, only units whose mean voltage at detection was at least 2.5 SD away from that channel's threshold for detection were used, to minimize the floor effect from small units that dropped below threshold.

The probability that each spike arose from its assigned peri-ictal unit was calculated by fitting a separate Gaussian curve (with a maximum amplitude of 1) to the distribution of voltages at each data point in the original unit, and calculating the mean probability across all time samples. As such, a waveform passing through the most likely voltage at each separate time point for that unit would have a match probability of 1 (Fig. 3). Instantaneous firing rates were calculated by convolving the spike times with a Gaussian kernel (200 ms SD) with the amplitude scaled to that spike's probability of matching the original unit, thereby creating probabilistic firing rates for each unit through time, by probability of when the spike occurred and probability that the spike originated from the putative neuronal source. As such, a waveform that had an average probability of $20 \%$ across all fitted Gaussians from each data point would contribute only 0.2 spikes s${ }^{-1}$ at its most likely time point, while an exact match to the most likely voltage at

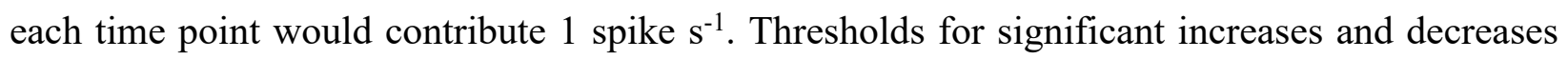
in firing rate were calculated as 3 times the square root of the firing rate divided by the duration of the epoch, which approximates 3 SD for a Poisson distribution.

Timing of FWHM alteration relative to the earliest ictal activity was determined by the earliest timepoint during the seizure that the mean FWHM remained above the preictal mean 
172 plus the preictal standard deviation for at least 1 second, calculated in a sliding window of $5 \mathrm{~s}$

173 duration with a time step of $50 \mathrm{~ms}$, discarding windows with fewer than 5 spikes.

All statistical tests for significance were performed using the Mann-Whitney $U$ test unless otherwise noted, due to the non-Gaussian distributions of data requiring non-parametric

176 testing. For all tests, the level for statistical significance $(\alpha)$ was set to 0.05 , and Holm-

177 Bonferroni correction was applied in all instances of multiple tests.

Results

We analysed ictal recordings from 27 patients undergoing invasive EEG monitoring as

180 part of the presurgical evaluation for intractable focal epilepsy (Tables $1 \& 2$; age range $=19$ to

$18155 ; 13$ female, 14 male). Six patients were implanted with Utah microelectrode arrays (UMA;

182 Blackrock Microsystems Inc, Salt Lake City, UT), and the remaining 21 patients were implanted

183 with between 1 and 4 Behnke-Fried depth arrays with incorporated microwire bundles (BF

184 arrays; Ad-tech Medical Equipment Corp, Oak Creek, WI). A total of 41 seizures were reviewed

185 (10 UMA; 31 BF array), of which 27 demonstrated ictal recruitment through MUA firing rate

186 calculation in UMAs, or subsequent waveform alterations in BF arrays (see Methods; UMA: 6

187 seizures from 3 patients; BF arrays: 21 seizures from 13 patients).

\section{Dual activity types at seizure onset}

To assess the presence of physiological spike shape changes across populations of

190 neurons, template matching using convex hulls (Fig. 2, see Methods) was employed on each

191 UMA-recorded seizure (Table 1; 1,107 single units in total; range of units per seizure: 61 - 240;

192 mean \pm SD maximum units per patient: $122 \pm 63$ ). The convex hull fits a 3-dimensional region

193 around the peri-ictal unit's cluster in principal component space, within which waveforms are

194 assigned as a putative match to that neuron. This allows for assigning unit identities without the

195 need for maintained cluster boundaries in the data, while accepting waveform alterations that 
alter the principal component scores. In total, 938 of the 1,107 units recorded on UMAs were successfully tracked through seizures using this method. spike full-width at half maximum (FWHM; Fig. 4, ictal waveforms in red), and were stereotyped across seizures within patient (Fig. 5). At the population level, units in recruited cortex displayed a significant global increase in FWHM (Fig. 6A; pre-ictal vs. ictal mean \pm SD: $0.470 \pm 0.137 \mathrm{~ms}$ increase in FWHM during the seizure (Holm-Bonferroni corrected Mann-Whitney U test; range across seizures: 79\% - 97\%; see Table 3). Meanwhile, units in penumbral cortex showed only a minor increase in FWHM at the population level (Fig. 6B; pre-ictal vs. ictal mean \pm SD: $0.414 \pm$ $0.009 \mathrm{~ms}$ vs. $0.429 \pm 0.099 \mathrm{~ms})$ with only $9(5.8 \%)$ of 156 single units showing a significant $(p<$ 0.05) increase in FWHM during the seizure (Holm-Bonferroni corrected Mann-Whitney U test; range across seizures: $4 \%-16 \%$; see Table 3 ). In a single case (Patient 6 ), the UMA was at the

210 edge of the clinically defined ictal spread, and in this patient $105(47.5 \%)$ of 221 units showed a

211 significant increase in FWHM (pre-ictal vs. ictal mean \pm SD: $0.408 \pm 0.111$ ms vs. $0.421 \pm 0.152$

$212 \mathrm{~ms})$. These spike shape alterations co-existed with stable spike shapes elsewhere on the UMA at 213 the same time (Fig. 7), and this patient was incorporated into the penumbral dataset for

214 population representation in the figures (Fig. 6). FWHM increases in recruited tissue were 215 significantly larger than those in penumbral/edge case recordings $(p<0.001$; one-tailed Mann216 Whitney U test).

217 Similarly, units in recruited cortex showed a significant decrease in spike amplitude 218 during the seizure (Fig. 6C; pre-ictal vs. ictal mean \pm SD: $48.82 \pm 30.91 \mu \mathrm{V}$ vs. $34.96 \pm 19.54$ $219 \mu \mathrm{V}$ ), while penumbral recordings maintained their peri-ictal amplitude (Fig. 6D; pre-ictal vs. 
ictal mean \pm SD: $46.69 \pm 16.59 \mu \mathrm{V}$ vs. $45.08 \pm 15.05 \mu \mathrm{V}$ in fully penumbral cases; $47.00 \pm 21.18$

$221 \mu \mathrm{V}$ vs $45.57 \pm 20.93 \mu \mathrm{V}$ in the semi-recruited UMA). The amplitude reduction in recruited tissue

222 was significantly greater than in penumbral/edge case recordings $(\mathrm{p}<0.001$; one-tailed Mann-

223 Whitney $U$ test), with recruited recordings showing significant $(p<0.05)$ decreases in amplitude

224 during the seizure in $49.3 \%$ of units versus $6.4 \%$ of units in the penumbra and $38.9 \%$ in semi-

225 recruited tissue (Holm-Bonferroni corrected Mann-Whitney U test).

\section{Spike shape changes in deep structures}

To assess the spatiotemporal relationship between waveform alterations and seizure recruitment within patients, beyond the capabilities of the $4 \mathrm{~mm}^{2}$ Utah array, we analysed $\mathrm{BF}$ array recordings with the equivalent template matching, blind to the clinically-defined seizure onset zone and areas of propagation. In BF array recordings, 120 of 132 units were successfully tracked using these methods. Thirty of 120 single units $(25.0 \%)$ showed increases beyond a cut-

232 off significance level of $p<0.05$ (Holm-Bonferroni corrected Mann-Whitney U test) in FWHM

233 (17 seizures from 13 patients), and 30 units $(25.0 \%$; 16 seizures from 11 patients) showed

234 reduction in spike amplitude below the same significance cut-off ( $p<0.05$; Table 2). In 9

235 seizures from 6 patients, single units were simultaneously present on multiple separate BF arrays

236 (on different bundles of microwires, as opposed to different microwires within a single BF), of

237 which 7 seizures (6 patients) showed waveform alterations in at least one unit. Of these, 2 238 seizures (2 patients) showed significant waveform alterations in dual locations (Patients 14 and 239 15; Fig. 8; Table 2), while 5 seizures (4 patients) showed both activity types simultaneously 240 (Patients 11, 12, 16 and 21; Video 1).

241 We found significant waveform alterations in 13 patients. Five of these had a clinically 242 defined SOZ in the mesial temporal lobe, and simultaneously recorded single units in the 243 ipsilateral hippocampus demonstrated significant waveform alterations (Patients 8, 15, 16, 26 \& 
27; Table 2). In 7 further patients, significant waveform alterations were found in tissue

245 consistent with putative seizure spread due to proximity to the SOZ, or due to seizure

246 generalization. In one case (Patient 10) we found waveform alterations in the contralateral

247 hippocampal body, consistent with propagation of the seizure through the hippocampal

248 commissural fibers. Conversely, in the 8 patients showing no significant waveform alterations,

249 the clinically defined SOZ was anatomically distant in all cases (Patients 9, 13, 17-20, 24 \& 25;

250 Table 2).

To assess whether the classification of ictal recruitment via waveform alterations was

consistent with the clinically defined SOZ and regions of spread, the time from earliest ictal

253 activity to a consistent ( $\geq 1 \mathrm{~s}$ duration) increase in FWHM $\geq 1$ SD above the mean preictal level

254 for each unit was calculated. FWHM was used independently of amplitude for these tests to

255 control for any potential fluctuations in amplitude introduced by the reference electrode during

256 seizures. Recordings determined to be in the SOZ showed a mean ( \pm SD) delay of $10.23 \pm 3.03 \mathrm{~s}$

257 ( $n=6$ seizures from 5 patients), while those deemed to be in regions of spread showed a mean $( \pm$

$258 \mathrm{SD})$ delay of $22.96 \pm 12.59 \mathrm{~s}(n=8$ seizures, 8 patients; $p<0.05$, Mann-Whitney $\mathrm{U}$ test $)$. In one

259 case, single unit waveforms remained stable throughout a focal to bilateral tonic-clonic seizure

260 (Patient 18; Table 2), further countering the possibility of transient movement artefact 261 introducing instability in the waveforms.

262 In one instance of a patient recorded with BF arrays in the hippocampal head and body, a

263 peculiarly discrete unit cluster due to a very large amplitude spike (mean $=354 \mu \mathrm{V}$; background

264 noise level $=25 \mu \mathrm{V}$ ) enabled us to follow its action potential through the ictal transition without

265 the need for template matching via convex hulls, despite marked changes to spike shape and

266 increases in other unit activity (Fig. 8; Video 2; Schevon et al., 2019). In this example, the

267 seizure initiated very close to, but not at the electrode site. The ictal wavefront arrived at the 
electrode approximately $8 \mathrm{~s}$ after seizure initiation (Patient 15; Table 2). The action potential amplitude was stable during both the pre-ictal period and the moments after seizure initiation, but reduced sharply upon the abrupt increase in firing rate indicating ictal recruitment (Fig. 8A \& $\mathrm{B}$, magenta dashed line; preictal vs. ictal mean $\pm \mathrm{SD}: 354.2 \mu \mathrm{V} \pm 45.7 \mu \mathrm{V}$ vs. $265.7 \mu \mathrm{V} \pm 33.4$

$272 \mu \mathrm{V} ; p<0.001$, Mann-Whitney $\mathrm{U}$ test). The inter-spike interval to spike amplitude relationship 273 was similar to animal models of recruitment (c.f. Supplementary Fig. 4 in Merricks et al., 2015;

$2740 \mathrm{Mg}^{2+}$ in vitro cell-attached mouse slice model), and echoed the template matched results in the 275 Utah array (note the similarity between Fig. 4B and Fig. 8D).

Notably, a separate single unit recorded at an adjacent BF array showed spike shape

278 The distinct time course of these two units recorded in the hippocampal head and body show that

279 the alterations are unit-specific and not caused by local changes as a result of the seizure or by 280 movement artefacts (the seizure had a relatively calm semiology, without stressing the recording 281 device).

Simultaneously, action potential FWHM was stable prior to ictal recruitment, increasing 283 significantly after the passage of the ictal wavefront (preictal vs. ictal mean \pm SD: $0.33 \mathrm{~ms} \pm 0.04$ 284 ms vs. $0.40 \mathrm{~ms} \pm 0.05 \mathrm{~ms} ; p<0.001$, Mann-Whitney $\mathrm{U}$ test). The time course of this transition 285 followed the same progression as the spike amplitude (Fig. 8D), as can be seen in the prerecruitment versus post-recruitment mean $( \pm \mathrm{SD})$ waveforms (Fig. $8 \mathrm{C}$, blue and red respectively).

287 Template matching accuracy

Spike matches from the convex hull method were found to be significantly more likely to

289 arise from their assigned peri-ictal units than by chance, as calculated by comparing each 290 matched waveform's similarity to its peri-ictal unit's distribution of voltages through time (Fig.

291 3; "Spike metrics" in Methods). The "null" distribution for expected match probabilities by 
chance was calculated through comparing each waveform's similarity to the peri-ictal voltagetime distributions of all other units. Comparing intra- to inter-unit similarities in this way found a significantly higher similarity between template matched units and their presumed peri-ictal unit than to the "null" distribution of matches to other units $(p<0.001$; Mann-Whitney U test; Fig. 3B).

To confirm that these findings were not a result of the template matching method introducing an unknown variable that affects these measurements, results from the original spike sorted data and those originating from the convex hull method on the pre-ictal period were compared, finding little difference between the traditional cluster cutting results and the convex

301 hull matched results (Fig. 6 A-D i, inset cumulative histograms).

\section{Neuronal firing rates through the ictal transition}

In animal models, it is possible to isolate single units experimentally, by visually guiding

304 electrodes directly onto cells (Trevelyan_ent_a $\underline{l}_{2}$ 2_2006). This obviously is not possible in human

305 recordings, and consequently, there is a dearth of evidence about the firing patterns of human

306 neurons through seizures. Instead, previous studies have identified the ictal wavefront in terms of

307 multi-unit activity (Schevon et al., 2012; Smith et al., 2016). We therefore analysed the firing

308 rates of template matched unit populations throughout ictal activity and related these to the ictal

309 wavefront (UMA recordings showing tonic to clonic firing; Patients 3-5; see Methods). Single

310 unit firing rate increased during ictal recruitment in all seizures with 446 (79.5\%) of 561 units

311 showing greater than $3 \mathrm{SD}$ increase in firing rate, and only 1 unit in the entire population

312 showing a greater than 3 SD decrease in firing rate (range of single units with $>3$ SD increase

313 per seizure: $70 \%-96 \%$; see Table 3). An example seizure demonstrating these trends is shown 314 in Fig. 9. 


\section{Discussion}

316 The analyses presented here explored the impact of spike shape alterations in

317 spontaneously occurring seizures, in humans, how these alterations relate to the underlying ictal

318 territories, and whether the ictal wavefront - the source of seizure propagation - involves local

319 neuronal firing or is dominated by subthreshold or synaptic activity. We have previously shown

320 that traditional spike sorting methods fail upon ictal invasion of the recording site (Merricks et

321 al., 2015), however, in these recordings it was not possible to differentiate between loss of spike

322 sorting ability due to intrinsic waveform alterations, or due to hypersynchronous activity

323 (Trevelyan et al., 2006, 2007; Schevon et al., 2012; Weiss et al., 2013). Here, we sought to

324 overcome this limitation through novel methods to track units through the ictal transition,

325 retaining the identities of putative individual neurons. We hypothesized that the temporary loss

326 of clusters was due in part to transient alterations to spike shapes, as opposed solely to

327 obfuscation of stable spike shapes by the sudden increase in activity in the MUA, and that units

328 at brain sites not demonstrating evidence of ictal recruitment via tonic firing in the MUA would

329 remain stable.

330 We applied this method in two types of microelectrode recordings: UMA and BF arrays, 331 representing neocortical and deep structure, particularly hippocampal, seizure foci. Although

332 there must be some expected loss of detection sensitivity due to interference from highly

333 synchronous firing along with the reduction of amplitude of some units below the noise threshold,

334 the method proved remarkably effective, enabling us to define firing rate metrics for the majority

335 of units throughout the seizure, highlighting a lack of neuronal quiescence during seizures.

336 In both types of recording, template matched units during the ictal period displayed two

337 types of activity: deformation of waveshapes across the population, or largely stable waveforms.

338 The UMA afforded the ability to detect local ictal recruitment through characteristic MUA firing, 
and these types of activity corresponded to recruitment and penumbral recordings respectively

(Fig. 6). Waveform alterations recovered after seizure termination and showed a stereotyped response across seizures, highlighting that a single neuron's wave shape change, in response to

342 the synaptic barrage of upstream ictal activity, is maintained across multiple seizures hours apart.

343 Note that the template matching method would equally favor alterations to waveform in any

344 dimension, and so if these changes were purely a result of the methodology, we would

345 reasonably expect the template to capture spikes with larger amplitude and decreased FWHM at

346 an equal rate. In such a case, we would anticipate a broadening of the distribution of these

347 features during the ictal period. Instead, we see a clear shift in the distributions to the right and

348 left in the FWHM and amplitude respectively, and found no evidence of increased spike

349 amplitude during seizures, arguing for a consistent physiological cause (Fig. 6A\&C).

Detection of the ictal wavefront was not possible in BF arrays, due to a combination of

351 lower neuronal density in mesial structures relative to layer 4/5 neocortex (Pakkenberg \&

352 Gundersen, 1997; Keller et al., 2018), and a reduced "listening sphere" relative to UMAs due to

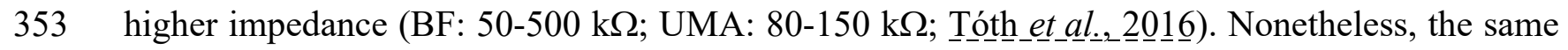

354 waveform features were detected, and their presence correlated well with the clinical assessment

355 of SOZ and seizure spread (Table 2). Furthermore, BF arrays allowed for sampling of multiple

356 sites in a given patient, and the timing of waveform alterations correlated well with clinical

357 observations, with seizure spread locations showing delayed waveform changes compared to

358 recordings from SOZ regions (22.96 vs. 10.23 s respectively). The longest delay until

359 recruitment occurred after spread to the contralateral hippocampus (Patient 10; $42.7 \mathrm{~s}$ ). The only

360 case with discordance between single unit and clinical data showed a statistically significant

361 increase in FWHM during the seizure, but at no point did the mean FWHM surpass the threshold

362 of $1 \mathrm{SD}$ above the preictal mean (Patient 21; Table 2). In this instance, the clinical SOZ was in 
363 the right insula and somatosensory cortex, with waveform alterations in the right hippocampus.

364 While recruitment of the hippocampus is plausible, this may represent a false positive as a result

365 of the temporally coarse statistical test.

The UMA and BF array recordings together provide evidence supporting the dual-territory model of seizures: an ictal core with waveform changes, coexisting with a penumbral territory with stable spike shapes. Combined, these indicate that the definitions of ictal recruitment and penumbra are maintained at the level of single neurons, and waveshape change can be considered a defining feature of recruitment to the seizure. In a subset of recordings, stable action potentials were found simultaneously with waveform changes both in separate BF arrays

372 (5 seizures) and on the same UMA (1 seizure; Patient 6), with clinical correlation matching these

373 observations in all cases. In the UMA, clinical observations were consistent with location of the

374 UMA at the outer boundary of seizure invasion, and thus we posit this is a simultaneous 375 recording of both recruited and penumbral cortex (Fig. 7).

Furthermore, in 2 seizures, recruitment was found at multiple BF arrays, consistent with

377 clinically defined SOZ and regions of spread, along with relative delays in keeping with 378 anatomical distance (Fig. 8; Patients 14 \& 15; mid-cingulate to hippocampus in $10.3 \mathrm{~s}$, 379 hippocampal head to body in $1.1 \mathrm{~s}$ respectively). Note also, that in Patient 6 there is an increase 380 in waveforms of brief duration during the ictal period (data available online; population data 381 shown in Fig. 6B). Given the UMA's proximity to the oncoming ictal wavefront, this increase 382 may be explained by an increase in firing of fast-spiking interneurons, which have been shown to 383 exhibit action potentials of shorter duration (McCormick \& Feeser, 1990; Csicsvari et al., 1999; 384 Peyrache et al., 2012) and would corroborate the penumbral feedforward inhibition model 385 (Trevelyan et al., 2007; Cammarota et al., 2013; Parrish et al., 2019). 
More specifically, the waveform changes found in recruited tissue are in keeping with those observed in animal models, and are indicative of the shortening and broadening of action potentials associated with PDS (Traub \& Wong, 1982). This was especially evident in a unique $\mathrm{BF}$ array recording wherein a unit was able to be tracked without need for extra methods due to its amplitude being 14 times that of the background noise (Patient 15; Fig. 8), with feature alterations strikingly reminiscent of the UMA population data (c.f. Figs. 4B \& 8D), with timing in keeping with recruitment, during tonic firing (c.f. Figs. $7 \& 8$ ).

Even so, the extent to which these waveforms alter is likely underrepresented in the population data, due to changing detection sensitivity from interference between synchronous spikes or the reduction of amplitude of some spikes below the noise threshold. The templatematching method was designed to minimize false negatives in order to capture as much single unit activity during seizures as possible, but it is likely that spikes undergo large enough changes to be lost outside the convex hull, or below threshold. Indeed, even physiological bursting has been shown to result in substantial alterations to extracellularly recorded action potentials (Harris et al., 2000; Henze et al., 2000). As such, these results are necessarily a snapshot of the total

401 activity of any individual neuron during the seizure, and yet still show significant changes to 402 waveform.

Finally, our data also demonstrate that the passage of the ictal wavefront is marked by tonic, 404 local neuronal firing (Fig. 9), as opposed to the wavefront being a signature of increased $\mathrm{K}^{+}$ 405 concentration or similar subthreshold phenomena. Studies of single unit activity recorded in 406 humans have rarely reported such a finding. Although placement of the electrodes likely plays a 407 large role, our findings in this paper suggest that extreme, rapid waveform alterations may 408 obscure the presence of the wavefront when standard spike sorting methods are used. Note that 409 these firing rate statistics are probabilistic, having been scaled by the probability each spike was 
410 a match to its preictal unit (see Methods), and as such are conservative and thus the increase

411 cannot be attributed purely to increases in background spikes being matched by the convex hull

412 method.

413 This method of tracking single units across the ictal transition will enable the use of both

414 human and animal recordings to address open questions regarding the mechanism of seizure

415 spread. An immediate application, given the neuronal activity presented here, is to study how cell

416 types relate to the propagation of pathological activity, with considerable debate having focused

417 recently on the role of interneurons in seizure spread (Grasse et al., 2013; Elahian et al., 2018;

418 Magloire et al., 2018; Miri et al., 2018; Weiss et al., 2018). All studies to date, to our knowledge,

419 have assessed cell-type specific activity at seizure onset in regions without waveform alterations,

420 and thus we suggest are recordings from penumbral territories. As such, we anticipate elucidation

421 of these mechanisms will come from population data confirmed to be in recruited tissue. These

422 methods lay important groundwork for analyses into how ictal propagation relates to the

423 underlying firing of local inhibitory and excitatory cells. 


\section{REFERENCES}

425

426

Babb TL, Wilson CL \& Isokawa-Akesson M (1987). Firing patterns of human limbic neurons during stereoencephalography (SEEG) and clinical temporal lobe seizures. Electroencephalogr Clin Neurophysiol 66, 467-482.

Bower MR, Stead M, Meyer FB, Marsh WR \& Worrell GA (2012). Spatiotemporal neuronal correlates of seizure generation in focal epilepsy. Epilepsia 53, 807-816.

Cammarota M, Losi G, Chiavegato A, Zonta M \& Carmignoto G (2013). Fast spiking interneuron control of seizure propagation in a cortical slice model of focal epilepsy. The Journal of Physiology 591, 807-822.

Csicsvari J, Hirase H, Czurkó A, Mamiya A \& Buzsaki G (1999). Oscillatory coupling of hippocampal pyramidal cells and interneurons in the behaving Rat. Journal of Neuroscience 19, 274-287.

Eissa TL, Tryba AK, Marcuccilli CJ, Ben-Mabrouk F, Smith EH, Lew SM, Goodman RR, McKhann GM, Frim DM, Pesce LL, Kohrman MH, Emerson RG, Schevon CA \& van Drongelen W (2016). Multiscale Aspects of Generation of High-Gamma Activity during Seizures in Human Neocortex. eneuro 3, ENEURO.0141-15.2016-17.

Elahian B, Lado NE, Mankin E, Vangala S, Misra A, Moxon K, Fried I, Sharan A, Yeasin M, Staba R, Bragin A, Avoli M, Sperling MR, Engel J \& Weiss SA (2018). Low-voltage fast seizures in humans begin with increased interneuron firing. Annals of neurology 84, 588600 .

Fariello RG, Portera A \& Scheffner D (1976). Parenteral Penicillin in Rats: An Experimental Model of Multifocal Epilepsy. Epilepsia 17, 217-222.

Grasse DW, Karunakaran S \& Moxon KA (2013). Neuronal synchrony and the transition to spontaneous seizures. Experimental Neurology 248, 72-84.

Grone BP \& Baraban SC (2015). Animal models in epilepsy research: legacies and new directions. Nature neuroscience 18, 339-343.

Harris KD, Henze DA, Csicsvari J, Hirase H \& Buzsaki G (2000). Accuracy of tetrode spike separation as determined by simultaneous intracellular and extracellular measurements. Journal of Neurophysiology 84, 401-414.

Henze DA, Borhegyi Z, Csicsvari J, Mamiya A, Harris KD \& Buzsaki G (2000). Intracellular features predicted by extracellular recordings in the hippocampus in vivo. Journal of Neurophysiology 84, 390-400.

Hill DN, Mehta SB \& Kleinfeld D (2011). Quality metrics to accompany spike sorting of extracellular signals. The Journal of Neuroscience 31, 8699-8705.

Kandel ER \& Spencer WA (1961a). The pyramidal cell during hippocampal seizure. Epilepsia 2, 63-69. 
Kandel ER \& Spencer WA (1961b). Electrophysiology of hippocampal neurons. II. Afterpotentials and repetitive firing. $J$ Neurophysiol 24, 243-259.

Keller D, Erö C \& Markram H (2018). Cell Densities in the Mouse Brain: A Systematic Review. Frontiers in Neuroanatomy 12, 506-21.

Magloire V, Mercier MS, Kullmann DM \& Pavlov I (2018). GABAergic Interneurons in Seizures: Investigating Causality With Optogenetics. The Neuroscientist 35, 107385841880500-15.

Marcuccilli CJ, Tryba AK, van Drongelen W, Koch H, Viemari JC, Peña-Ortega F, Doren EL, Pytel P, Chevalier M, Mrejeru A, Kohrman MH, Lasky RE, Lew SM, Frim DM \& Ramirez J-M (2010). Neuronal Bursting Properties in Focal and Parafocal Regions in Pediatric Neocortical Epilepsy Stratified by Histology: Journal of Clinical Neurophysiology 27, 387-397.

Matsumoto H \& Marsan CA (1964). Cortical cellular phenomena in experimental epilepsy: Ictal manifestations. Exp Neurol 9, 305-326.

Merricks EM, Smith EH, McKhann GM, Goodman RR, Bateman LM, Emerson RG, Schevon

Miri ML, Vinck M, Pant R \& Cardin JA (2018). Altered hippocampal interneuron activity CA \& Trevelyan AJ (2015). Single unit action potentials in humans and the effect of seizure activity. Brain : a journal of neurology 138, 2891-2906. precedes ictal onset. eLife 7, 1277.

Pakkenberg B \& Gundersen HJ (1997). Neocortical neuron number in humans: effect of sex and age. The Journal of comparative neurology 384, 312-320.

Parrish RR, Codadu NK, Mackenzie Gray Scott C \& Trevelyan AJ (2019). Feedforward inhibition ahead of ictal wavefronts is provided by both parvalbumin- and somatostatinexpressing interneurons. The Journal of physiology 597, 2297-2314.

Peyrache A, Dehghani N, Eskandar EN, Madsen JR, Anderson WS, Donoghue JA, Hochberg LR, Halgren E, Cash SS \& Destexhe A (2012). Spatiotemporal dynamics of neocortical excitation and inhibition during human sleep. Proceedings of the National Academy of Sciences of the United States of America 109, 1731-1736.

Purpura DP, Penry JK, Tower DB \& Woodbury DM eds. (1972). Experimental models of epilepsy: A manual for the laboratory worker. Raven Press, New York.

493 Quian Quiroga R, Nadasdy Z \& Ben-Shaul Y (2004). Unsupervised Spike Detection and Sorting 
Schevon CA, Tobochnik S, Eissa T, Merricks E, Gill B, Parrish RR, Bateman LM, McKhann GM, Emerson RG \& Trevelyan AJ (2019). Multiscale recordings reveal the dynamic spatial structure of human seizures. Neurobiology of disease 127, 303-311.

Schevon CA, Weiss SA, McKhann G, Goodman RR, Yuste R, Emerson RG \& Trevelyan AJ (2012). Evidence of an inhibitory restraint of seizure activity in humans. Nature Communications 3, 1060-11.

Smith EH, Liou J, Davis TS, Merricks EM, Kellis SS, Weiss SA, Greger B, House PA, McKhann GM, Goodman RR, Emerson RG, Bateman LM, Trevelyan AJ \& Schevon CA (2016). The ictal wavefront is the spatiotemporal source of discharges during spontaneous human seizures. Nat Commun 7, 11098.

Stead M, Bower M, Brinkmann BH, Lee K, Marsh WR, Meyer FB, Litt B, Van Gompel J \& Worrell GA (2010). Microseizures and the spatiotemporal scales of human partial epilepsy. Brain 133, 2789-2797.

Steriade M \& Amzica F (1999). Intracellular study of excitability in the seizure-prone neocortex in vivo. Journal of Neurophysiology 82, 3108-3122.

Tóth E, Fabó D, Entz L, Ulbert I \& Erőss L (2016). Intracranial neuronal ensemble recordings and analysis in epilepsy. Journal of Neuroscience Methods 260, 261-269.

Traub RD \& Wong RK (1982). Cellular mechanism of neuronal synchronization in epilepsy. Science 216, 745-747.

Trevelyan AJ, Sussillo D, Watson BO \& Yuste R (2006). Modular propagation of epileptiform activity: evidence for an inhibitory veto in neocortex. The Journal of Neuroscience 26, $12447-12455$.

Trevelyan AJ, Sussillo D \& Yuste R (2007). Feedforward inhibition contributes to the control of epileptiform propagation speed. The Journal of Neuroscience 27, 3383-3387.

Truccolo W, Ahmed OJ, Harrison MT, Eskandar EN, Cosgrove GR, Madsen JR, Blum AS, Potter NS, Hochberg LR \& Cash SS (2014). Neuronal ensemble synchrony during human focal seizures. The Journal of Neuroscience 34, 9927-9944.

Truccolo W, Donoghue JA, Hochberg LR, Eskandar EN, Madsen JR, Anderson WS, Brown EN, Halgren E \& Cash SS (2011). Single-neuron dynamics in human focal epilepsy. Nature neuroscience 14, 635-641.

Weiss SA, Banks GP, McKhann GM, Goodman RR, Emerson RG, Trevelyan AJ \& Schevon CA (2013). Ictal high frequency oscillations distinguish two types of seizure territories in humans. Brain 136, 3796-3808.

Weiss SA, Staba R, Bragin A, Moxon K, Sperling M, Avoli M \& Engel J (2018). Interneurons and principal cell firing in human limbic areas at focal seizure onset. Neurobiology of disease 124, 183-188. 
bioRxiv preprint doi: https://doi.org/10.1101/2020.01.11.902817; this version posted January 19, 2020. The copyright holder for this preprint (which was not certified by peer review) is the author/funder. All rights reserved. No reuse allowed without permission.

NEURONAL ACTIVITY IN HUMAN SEIZURES

531 Wyler AR, Ojemann GA \& Ward AA (1982). Neurons in human epileptic cortex: correlation 532 between unit and EEG activity. Annals of neurology 11, 301-308. 


\section{FIGURES}

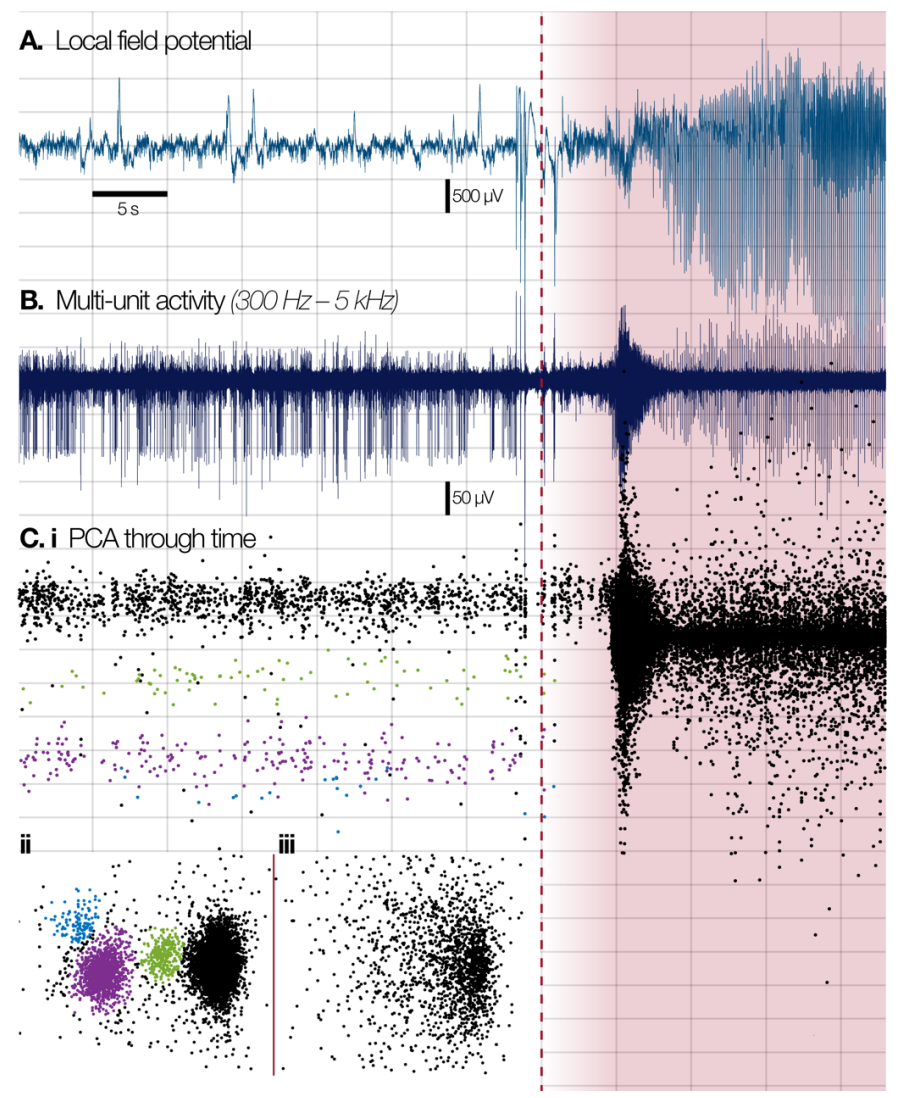

Fig. 1. Effects of ictal recruitment on traditional spike sorting methods

537 Spike sorting relies on stable waveforms from nearby neurons, but ictal activity disrupts features

538 used to cluster single units. A. Example broadband LFP from a single channel of a Utah array

539 implanted in the posterior temporal lobe of a patient with pharmacoresistant epilepsy (Patient 4,

540 seizure 1). Dashed red line denotes "global" seizure onset. B. Bandpass filtered signal between

$541300 \mathrm{~Hz}$ and $5 \mathrm{kHz}$ of the same signal in A, showing stable single unit activity in the preictal

542 period. C. First principal component score versus time (i) of all detected spikes in the multi-unit

543 activity shown in B, with three clearly separable clusters highlighted, along with the multi-unit

544 cluster from background distal cells (black). (ii) Equivalent first versus second principal

545 component scores from the preictal period, and (iii), during the seizure. Note loss of well-defined

546 clusters in principal component space. 


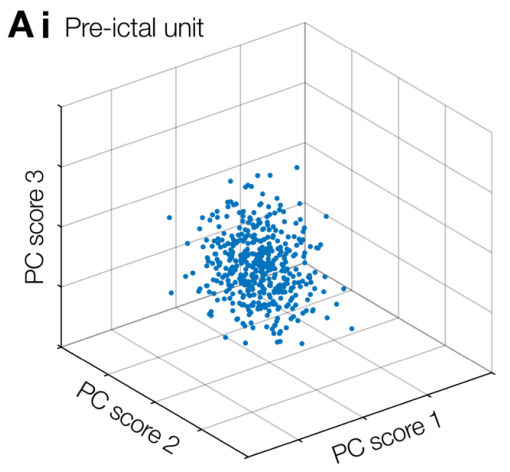

B i

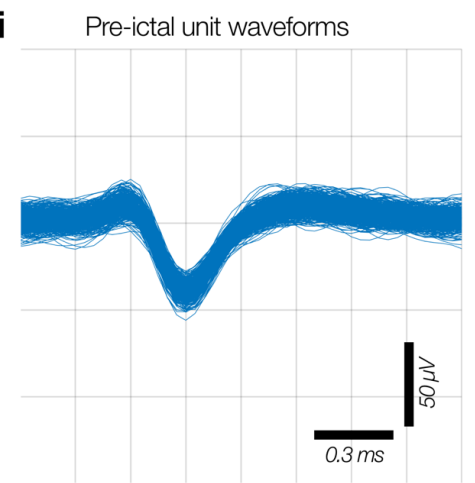

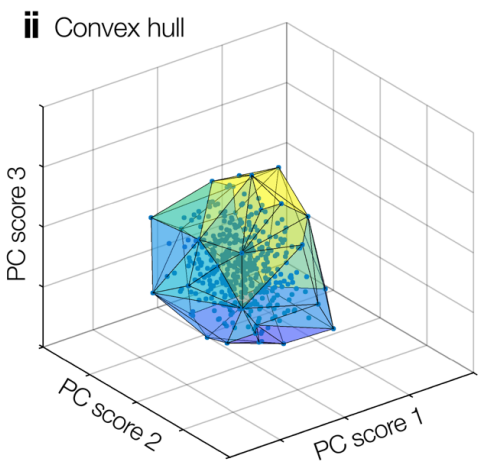

ii

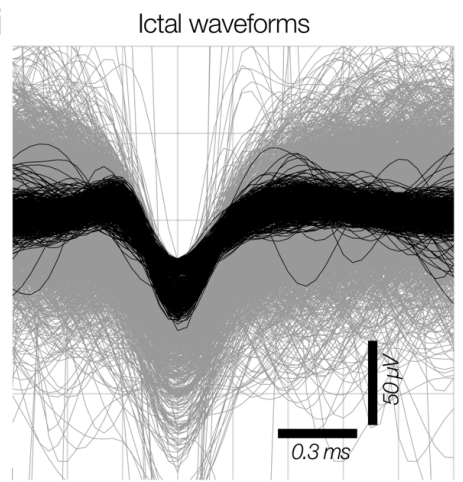

iii Ictal "unit"
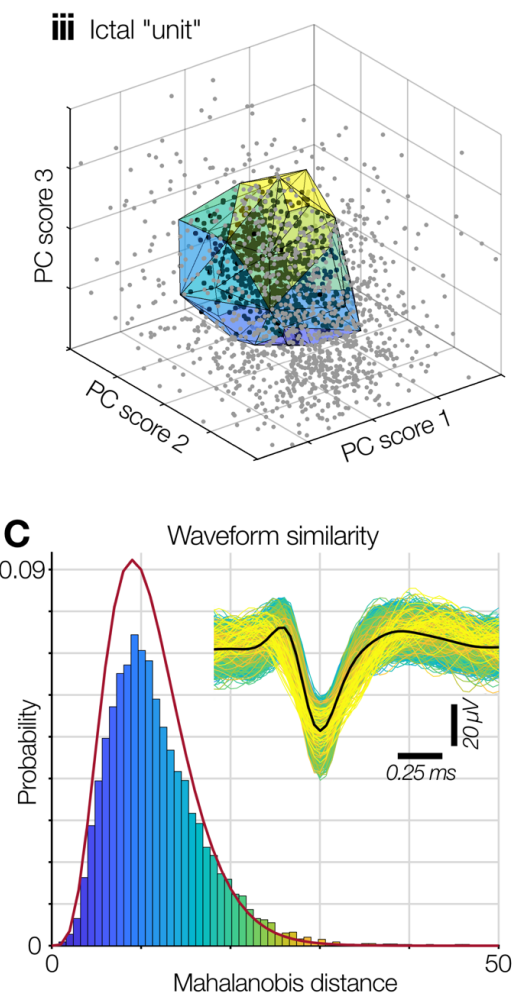

Fig. 2. Template match spike sorting via convex hulls

550 A. Well-isolated neurons form distinct clusters in principal component space during interictal

551 time points (i), around which a convex hull can be fitted to define boundaries in 3D space within

552 which spikes that match that unit should exist (ii). Despite a lack of defined clusters during ictal

553 activity in recruited cortex, this convex hull can be used to select waveforms that are likely to

554 correspond to the preictal unit (iii; black), amongst distributed noise (grey). B(i) Waveforms

555 from the preictal cluster shown in A(i). (ii) Waveforms matched using the convex hull shown in

556 A(iii) (black) from the large distribution of spikes during a seizure (grey). C. The probability of

557 each matched waveform originating from the same neuron as its preictal counterpart is calculated

558 by calculating their Mahalanobis distance from the preictal cluster using the first $n$ principal

559 components that explain $\geq 95 \%$ of the variance. Outliers in the chi-squared distribution for $n$

560 degrees of freedom denote likely incorrect matches. 


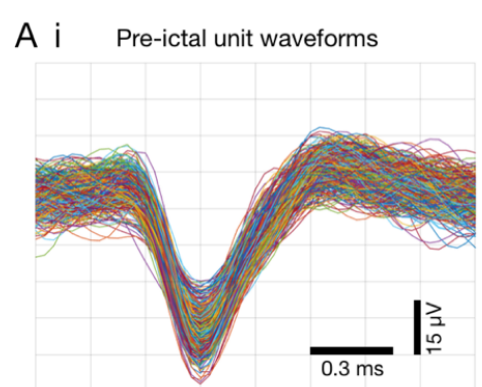

iii Ictal waveform probabilities

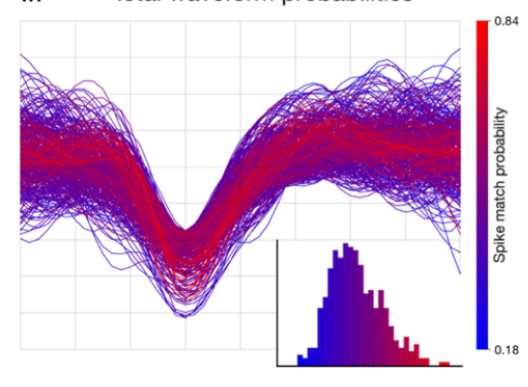

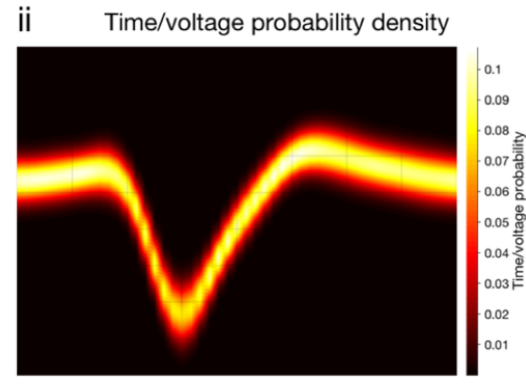

B Waveform match probabilities

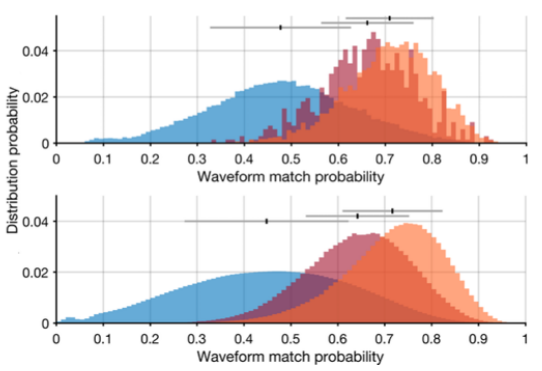

Fig. 3. Waveform match probabilities

563 A(i). All waveforms from a traditionally spike sorted unit in a 10 minute preictal epoch. The

564 probability distribution of each voltage at each time point for these waveforms is shown in (ii),

565 and the spike match probabilities for ictal waveforms matching this unit are shown in (iii), with

566 the distribution of these probabilities inset. B. Upper panel shows the probability distribution of

567 all matched waveforms (red), compared to the probability distribution for the original waveforms

568 in the preictal time point (orange) for an example template-matched single unit. A bootstrap

569 estimate of waveform matches expected by chance by comparing against waveforms from other

570 electrodes is shown in blue. The lower panel shows the equivalent distributions across the full

571 population. Mean $\pm \mathrm{SD}$ is shown above the distributions. 
A

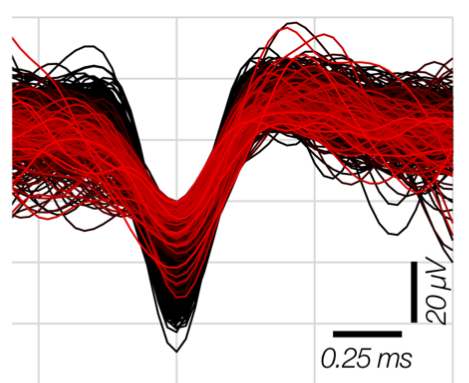

$$
\begin{aligned}
& \text { C } \\
& \text { 䇋 } \\
& \frac{0}{0} \\
& \frac{0}{8} \\
& \frac{8}{0} \\
& \frac{10}{3}
\end{aligned}
$$
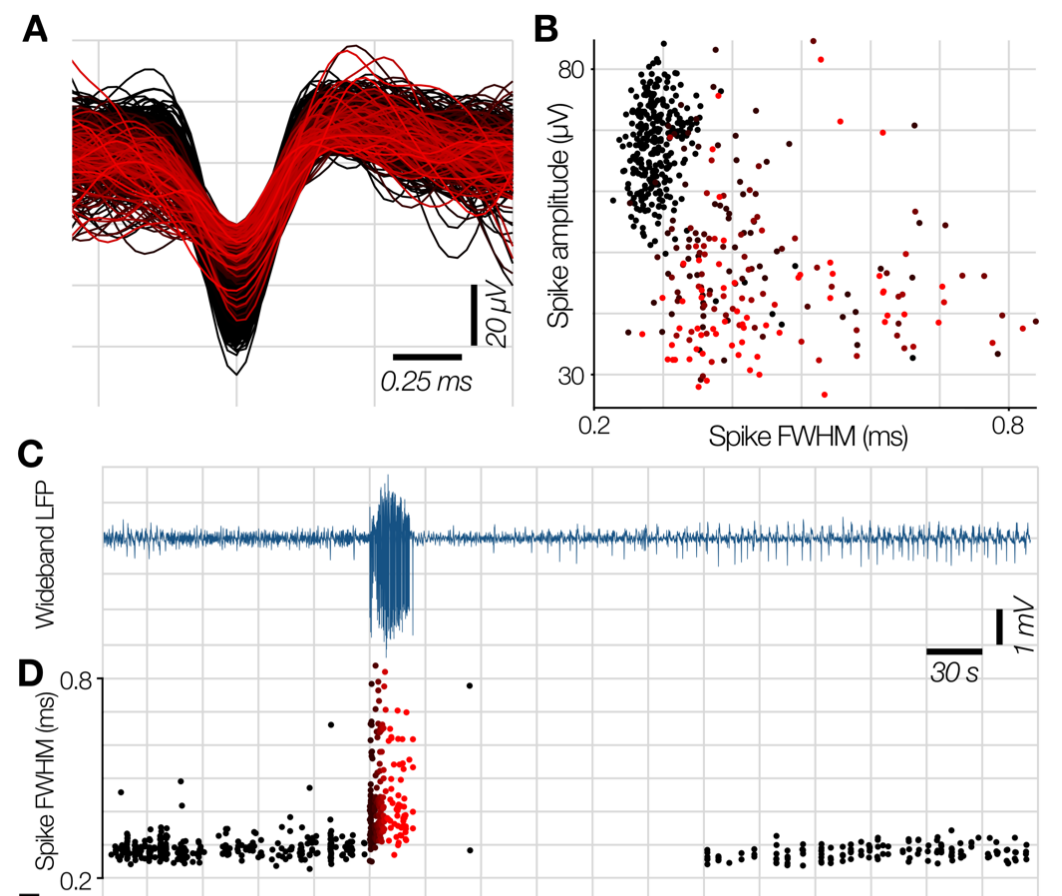

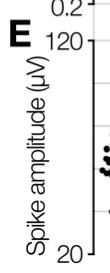

\subsection{1 ii ! lia! igje}

573

\section{Fig. 4. Example wave shape changes at ictal recruitment in template matched data}

A. Waveforms from a convex hull-matched unit in Patient 5, seizure 2, showing reduction in amplitude and increase in FWHM during the seizure (red shaded waveforms, fading from black to red through the seizure; color maintained throughout figure). FWHM in the unit in A, showing equivalent relationship to the high amplitude BF single unit in Fig. 8D. Wideband LFP from this channel through time (C), with time-locked FWHM (D) and amplitude (E) showing temporal relationship of spike shape changes through the seizure. Note the return to preictal values after seizure termination, and the lack of changes towards decreased FWHM or increased amplitude during the seizure despite the convex hull being equally permissive of alterations in any direction.

B. Spike amplitude versus 
A Patient 5, seizure 1, channel 48
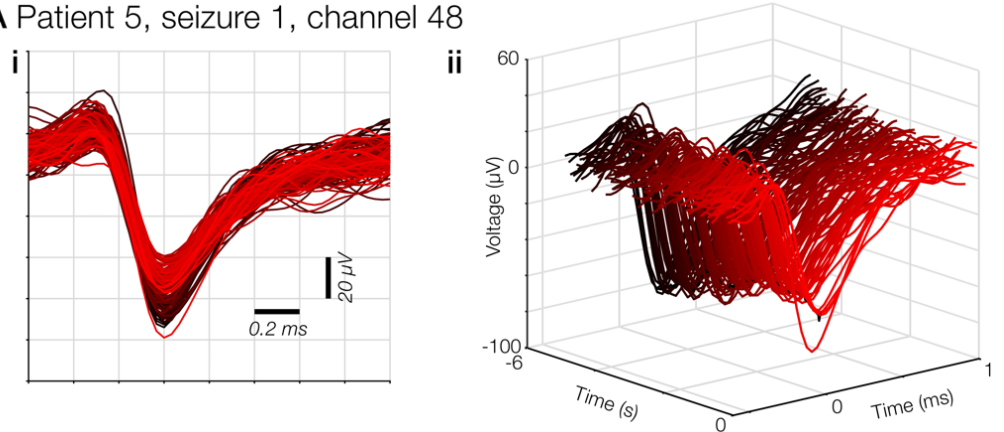

B Patient 5, seizure 2, channel 48
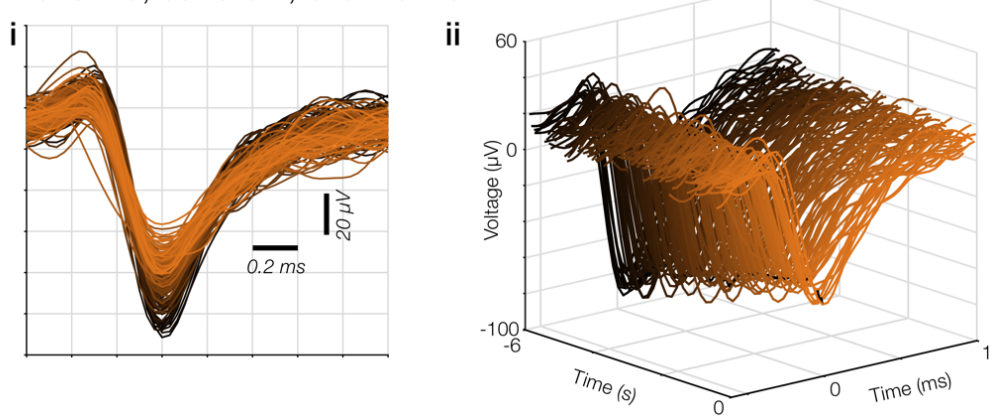

Fig. 5. Stereotypy of waveform changes within neurons across seizures

586 Example waveforms from a single unit in patient 5 showing stereotypy of response of

587 extracellularly recorded action potentials in the peri-recruitment period in 2 seizures separated by

58822 hours (A and $\mathbf{B}$ respectively). All waveforms from the 6 seconds prior to ictal recruitment are

589 shown overlaid in (i), and plotted relative to time in (ii), scales maintained throughout. Saturation

590 of color fades from black at -6 seconds, to brightest at the moment of maximal firing rate of

$591 \quad$ MUA at that electrode. 


\section{A. Recruited cortex FWHM}
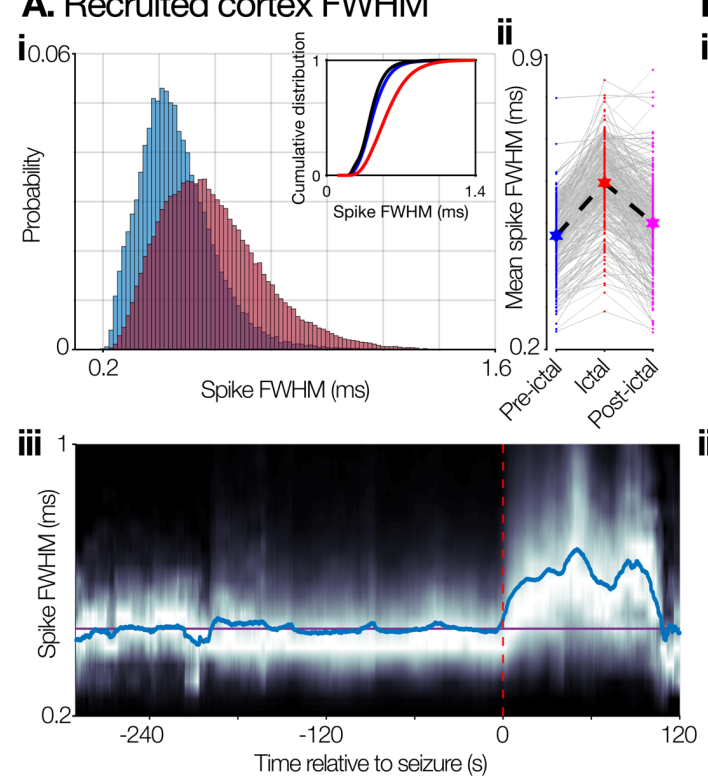

C. Recruited cortex amplitude
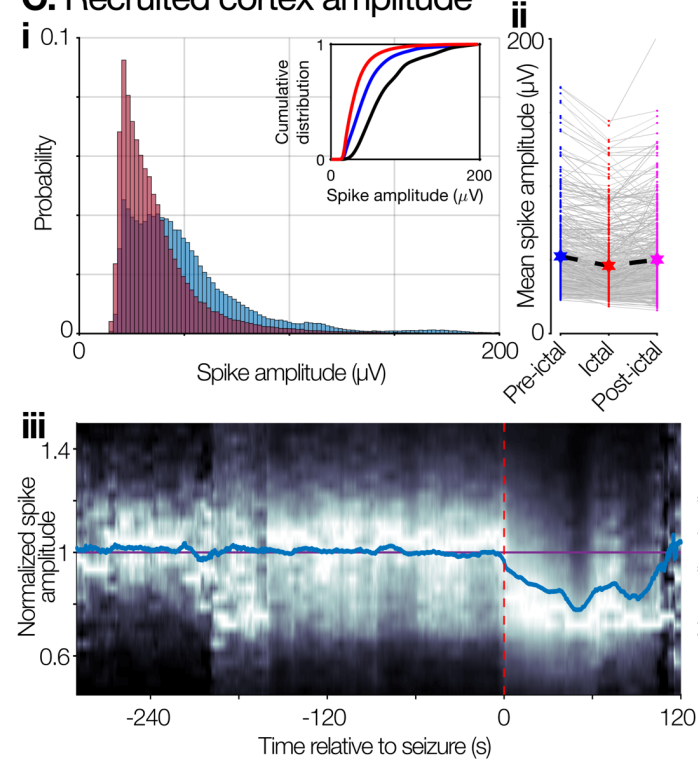
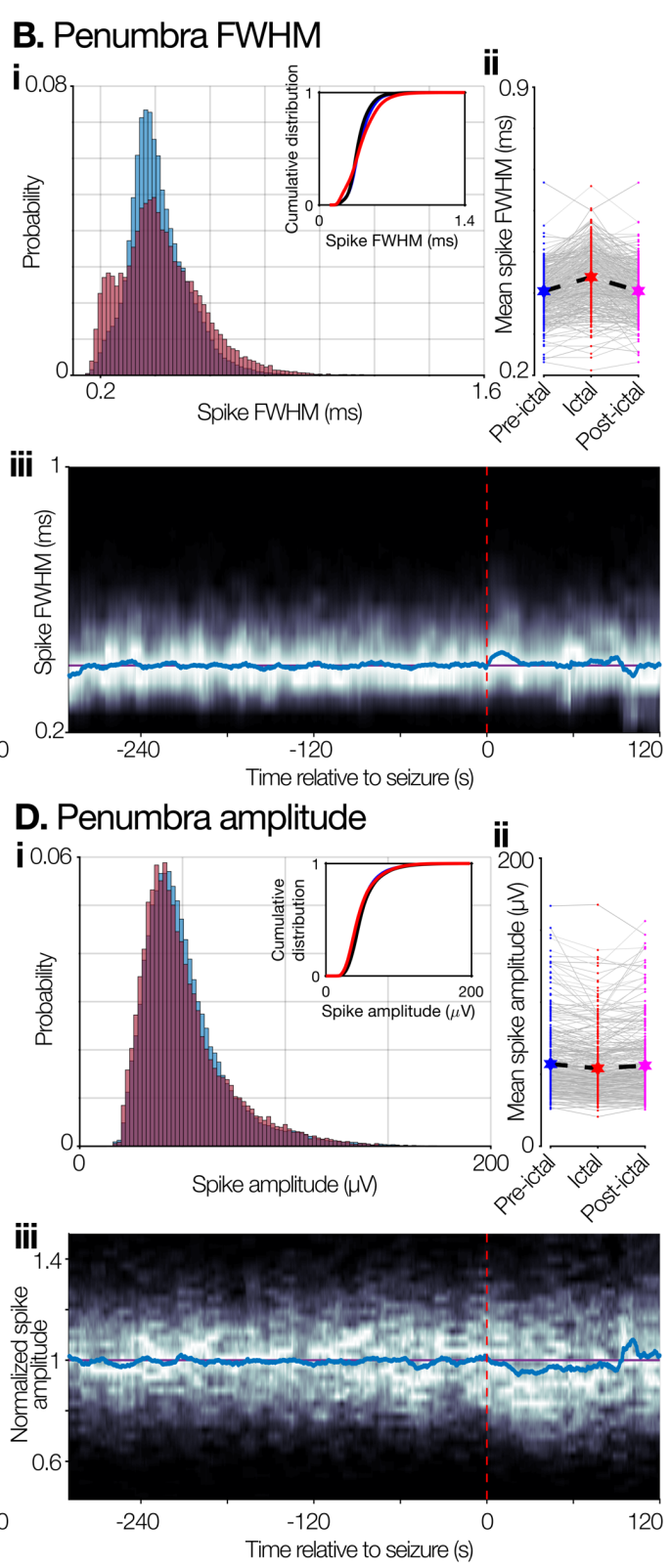

Fig. 6. Population spike shape alterations in recruited cortex versus penumbral territories

594 A \& B (i) Probability density plots of spike FWHM (full-width at half maximum) for every

595 detected waveform in the preictal (blue) and ictal time periods for all seizures in recruited cortex

596 (A; $n=625$ units from 6 seizures in 3 patients) and penumbral tissue (B; $n=405$ units from 4

597 seizures in 3 patients). Cumulative probability densities show same calculation on preictal,

598 original data (black), (ii) Paired mean FWHM for each unit in the preictal (blue), ictal (red), and

599 postictal (pink) epochs. Note return to preictal ranges after seizure termination. (iii) Spike 
FWHM of the population through time (10 second window, sliding every $100 \mathrm{~ms}$ ). Brighter

601 indicates more density, blue line shows the mean through time, purple line shows the mean value

602 in the preictal period, red dashed line denotes "global" seizure onset. C \& D. Same format as A

$603 \&$ B, showing spike amplitude in place of FWHM, for recruited cortex and penumbra

604 respectively.

605

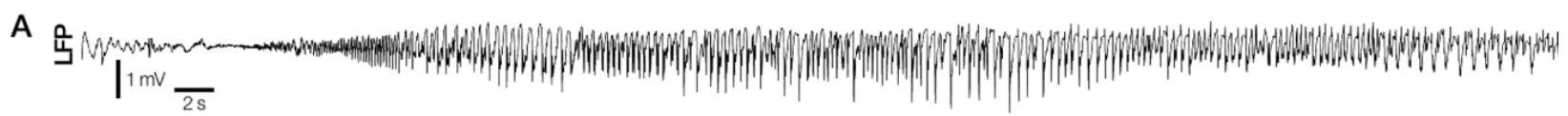

\section{$\mathrm{B} \leftrightarrows$}

क

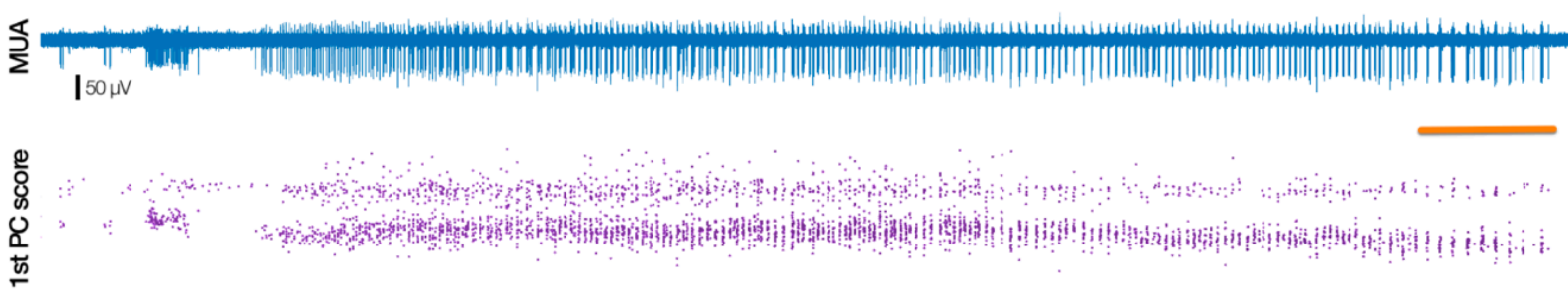

Fig. 7. Simultaneous recruitment and penumbral recording.

608 Two types of activity pattern recorded simultaneously in a patient with the Utah array at the edge

609 of the clinically defined seizure spread (Patient 6). A. LFP from the closest macro-electrode to

610 the UMA, with time-locked MUA (blue) and first principal component score (purple) through

611 time from channels 88 and 21 in $\mathbf{B} \& \mathbf{C}$ respectively. Note the stability of waveform and

612 principal component score throughout the seizure in channel 88, with no evidence of tonic firing,

613 while there is a large spike shape change at the same time in channel 21 , at the moment of tonic

614 firing (maroon bar, C). Paired orange bars in B and C denote burst firing at the end of the seizure

615 in both locations. These dual activity types both occurred immediately next to the LFP in A, and

616 thus these patterns cannot be differentiated at the macro LFP level. 
A i Local field potential

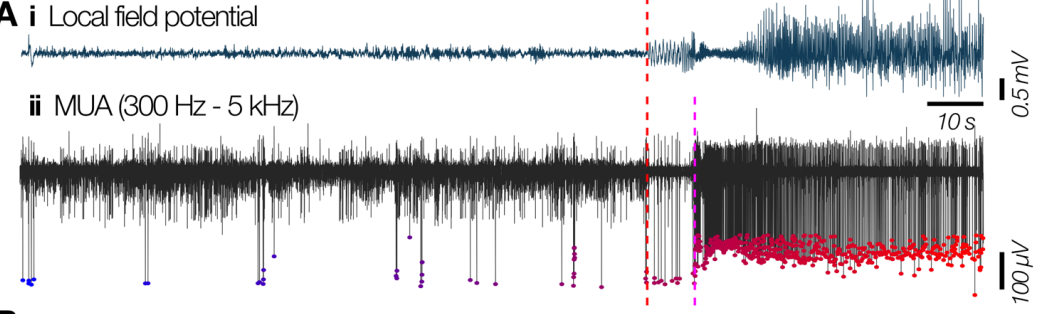

B

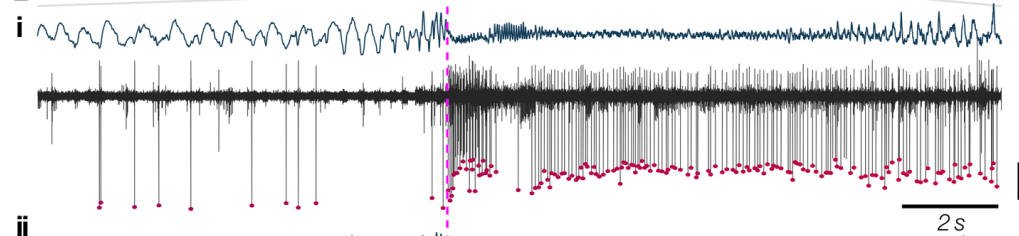

ii

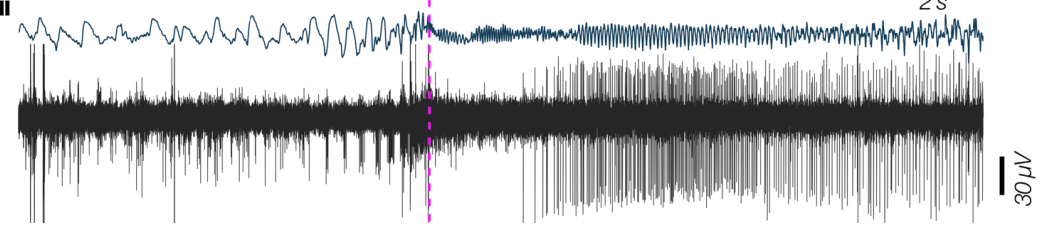

C

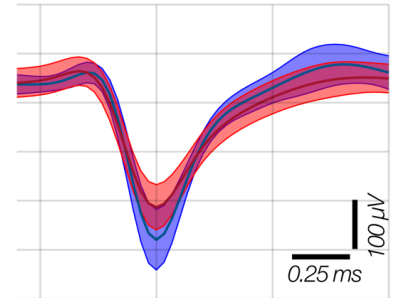

D

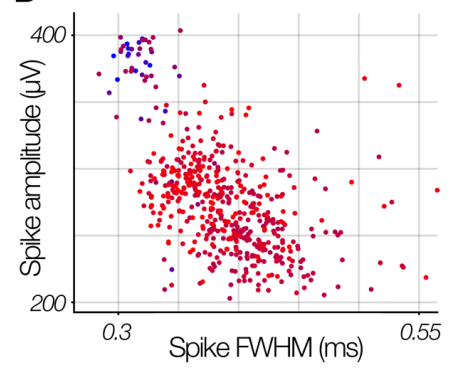

Fig. 8. Ictal recruitment in the mesial temporal lobe recorded with BF electrodes

620 A. (i) Broadband LFP from the closest macro contact to the microwires in a BF electrode in the mesial temporal lobe during a spontaneous seizure, and (ii) the bandpass filtered MUA from one of the microwires in the temporal pole. "Global" seizure onset is denoted by the red dashed line, with subsequent local recruitment to the seizure at the pink dashed line. B. Magnification of the

624 region denoted by the grey bar in A, showing seizure onset through passage of the ictal 625 wavefront in LFP and MUA (colours maintained) in the same microwire (i), and a microwire from a nearby separate BF in the hippocampal body (ii). Note the pre-recruitment stability in the

627 spike amplitude, which is immediately reduced upon ictal invasion, and the simultaneous 628 quiescence in the hippocampal body, followed by a similar, time-delayed amplitude change after 629 recruitment. C. Mean \pm SD of waveforms prior to ictal invasion (blue) and after recruitment 630 during the seizure (red), showing reduction in amplitude and increase in FWHM in A(ii). D. 631 Spike amplitude versus spike FWHM for the defined unit, with color maintained from A, 
632 transitioning from blue to red through seizure invasion. Note the bimodal clusters that 633 correspond to pre- and post-recruitment, and the similarity to Fig. 4B.

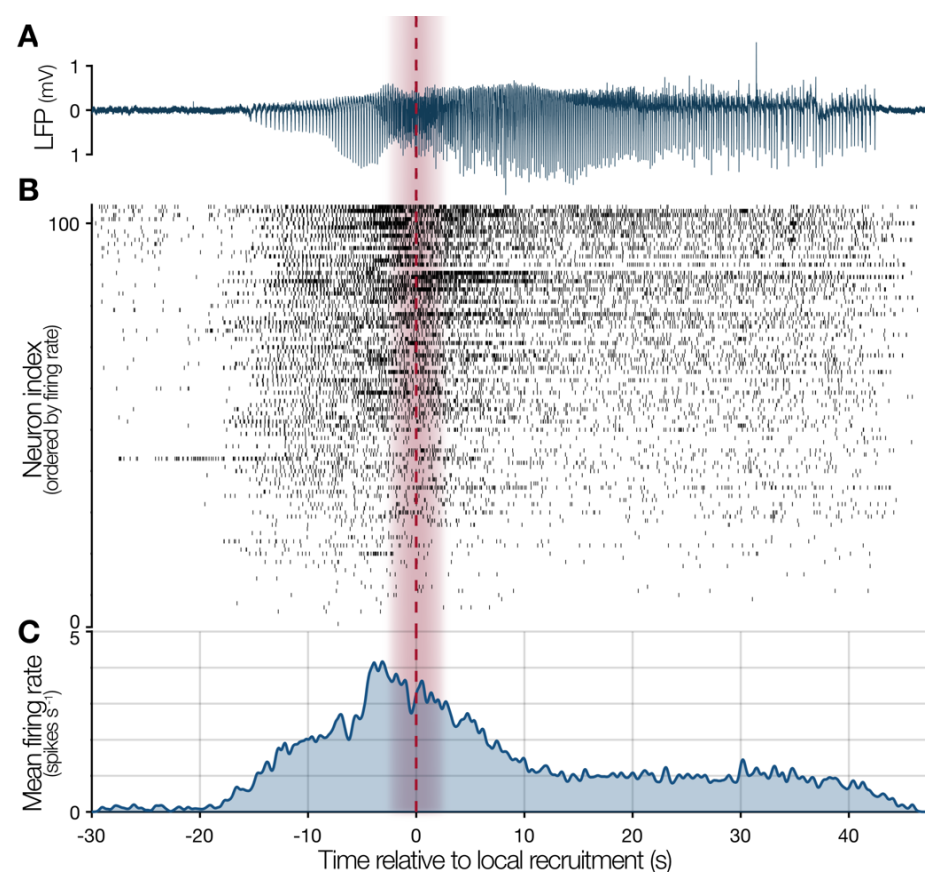

636 Fig. 9. Neuronal firing through ictal recruitment in an example focal seizure

637 A. Local field potential (LFP) from an example channel during seizure 1 in Patient 3, with the 638 calculated passage of ictal wavefront marked by red dashed line, with \pm 2 seconds shaded red. B.

639 Raster plot of all units found using convex hull template matching in this seizure, ordered by 640 firing rate, and plotted relative to the moment of ictal recruitment at that channel. C. Probabilistic

641 instantaneous firing rate of the population of single units as estimated by convolving a Gaussian

642 kernel (200 ms SD) over the spike times. The firing rate shown is probabilistic by scaling the

643 Gaussian kernel's amplitude by the likelihood of each individual spike originating from its 644 assigned preictal unit, as calculated by its voltage-time probabilities (see Methods \& Fig. 3). As

645 such, the firing rate has not been biased by excessive matching of dissimilar waveforms during 646 the ictal activity. Note the intense, tonic firing during the seizure invasion, and sustained, above 647 baseline firing until seizure termination. 
bioRxiv preprint doi: https://doi.org/10.1101/2020.01.11.902817; this version posted January 19, 2020. The copyright holder for this preprint (which was not certified by peer review) is the author/funder. All rights reserved. No reuse allowed without permission.

NEURONAL ACTIVITY IN HUMAN SEIZURES

648

TABLES

\begin{tabular}{|c|c|c|c|c|c|c|}
\hline Patient & Demographics & Implant location & $\begin{array}{l}\text { Seizure } \\
\text { type }\end{array}$ & Seizure onset & $\begin{array}{l}\text { Seizures } \\
\text { analyzed }\end{array}$ & \# units \\
\hline 1 & $30 \mathrm{M}$ & $\begin{array}{l}\text { Frontal } \\
\text { (Left frontal convexity) }\end{array}$ & $\mathrm{FIA}$ & $\begin{array}{l}\text { Left supplementary motor } \\
\text { area }\end{array}$ & 1 & 79 \\
\hline 2 & $39 M$ & $\begin{array}{l}\text { Frontal } \\
\text { (Left dorsolateral frontal lobe) }\end{array}$ & FIA & Left frontal operculum & 2 & {$[61,61]$} \\
\hline 3 & $25 \mathrm{~F}$ & $\begin{array}{l}\text { Temporal } \\
\text { (Left inferior temporal gyrus) }\end{array}$ & FIA & $\begin{array}{l}\text { Left basal/ } \\
\text { anterior temporal }\end{array}$ & 3 & {$[111,101,91]$} \\
\hline 4 & $19 \mathrm{~F}$ & $\begin{array}{l}\text { Temporal } \\
\text { (Right posterior temporal) }\end{array}$ & FTBTC & $\begin{array}{l}\text { Right posterior lateral } \\
\text { temporal }\end{array}$ & 1 & 110 \\
\hline 5 & $24 M$ & $\begin{array}{l}\text { Temporal } \\
\text { (Left inferior temporal gyrus) }\end{array}$ & FIA & $\begin{array}{l}\text { Left mesial temporal with } \\
\text { spread to lateral temporal }\end{array}$ & 2 & {$[120,133]$} \\
\hline 6 & $30 \mathrm{M}$ & $\begin{array}{l}\text { Temporal } \\
\text { (Right mesial temporal gyrus) }\end{array}$ & FA & Right subtemporal & 1 & 240 \\
\hline
\end{tabular}

649 Table 1. Demographics and data for patients implanted with Utah arrays

650 Individual patient demographics for grid/Utah array implant cases, including the number of

651 isolated single units found for each seizure in each patient. FIA: focal with impaired awareness;

652 FTBTC: focal to bilateral tonic-clonic.

653 
bioRxiv preprint doi: https://doi.org/10.1101/2020.01.11.902817; this version posted January 19,2020 . The copyright holder for this preprint (which was not certified by peer review) is the author/funder. All rights reserved. No reuse allowed without permission.

NEURONAL ACTIVITY IN HUMAN SEIZURES

\begin{tabular}{|c|c|c|c|c|c|c|c|c|c|}
\hline Patient & $\begin{array}{l}\text { Demogr } \\
\text { aphics }\end{array}$ & $\begin{array}{l}\text { Implant locations with } \\
\text { units }\end{array}$ & $\begin{array}{l}\text { Seizure } \\
\text { type }\end{array}$ & Seizure onset & $\begin{array}{l}\text { Seizures } \\
\text { analyzed }\end{array}$ & $\#$ units & $\begin{array}{l}\text { Microwires with } \\
\text { waveform alterations }\end{array}$ & $\begin{array}{l}\text { Time of } \\
\text { recruitment } \\
\text { (s) }\end{array}$ & $\begin{array}{l}\text { Clinical } \\
\text { correlation }\end{array}$ \\
\hline 7 & $29 \mathrm{~F}$ & $\begin{array}{l}\text { Mesial temporal } \\
\text { (Left hippocampus) }\end{array}$ & FTBTC & Left lateral frontal & 2 & {$[2,2]$} & Left hippocampus & 16.3 & Spread \\
\hline 8 & $29 \mathrm{~F}$ & $\begin{array}{l}\text { Mesial temporal } \\
\text { (Left hippocampus) }\end{array}$ & FA & Left mesial temporal & 2 & {$[2,1]$} & Left hippocampal head & 16.1 & $\sqrt{+}$ \\
\hline 9 & $55 \mathrm{~F}$ & $\begin{array}{l}\text { Mesial temporal } \\
\text { (Right hippocampus) }\end{array}$ & FIA & Right lateral temporal & 1 & 9 & - & - & $\sqrt{-}$ \\
\hline 10 & $25 \mathrm{M}$ & $\begin{array}{l}\text { Mesial temporal } \\
\text { (Left hippocampal body) }\end{array}$ & FIA & $\begin{array}{l}\text { Right mesial temporal } \\
\text { and right parietal } \\
\text { (dual) }\end{array}$ & 1 & 1 & Left hippocampal body & 42.7 & Spread \\
\hline 11 & $19 M$ & $\begin{array}{l}\text { Frontal } \\
\text { (Right anterior cingulate) }\end{array}$ & FIA & Right lateral temporal & 1 & 3 & $\begin{array}{l}\text { Right supplementary } \\
\text { motor area }\end{array}$ & 9.1 & Spread \\
\hline 12 & $20 \mathrm{~F}$ & $\begin{array}{l}\text { Frontal } \\
\text { (Left anterior \& mid- } \\
\text { cingulate) }\end{array}$ & FA & Left mesial temporal & 1 & 15 & Left mid-cingulate & 19.5 & Spread \\
\hline 13 & $21 \mathrm{~F}$ & $\begin{array}{l}\text { Mesial temporal } \\
\text { (Left hippocampus) }\end{array}$ & FA & $\begin{array}{l}\text { Left anterior temporal } \\
\text { pole }\end{array}$ & 1 & 1 & - & - & $\sqrt{-}$ \\
\hline 14 & $40 \mathrm{M}$ & $\begin{array}{l}\text { Mesial temporal/frontal } \\
\text { (Left hippocampus \& } \\
\text { anterior cingulate) }\end{array}$ & FIA & Left lateral frontal & 2 & {$[9,10]$} & $\begin{array}{l}\text { Left hippocampus; } \\
\text { Left mid-cingulate }\end{array}$ & $\begin{array}{l}39.3(\mathrm{HC}) \\
29.0(\mathrm{MC})\end{array}$ & Spread \\
\hline 15 & $25 \mathrm{~F}$ & $\begin{array}{l}\text { Mesial temporal } \\
\text { (Right hippocampus body } \\
\text { \& head) }\end{array}$ & FIA & $\begin{array}{l}\text { Right lateral temporal } \\
\text { spreading to mesial } \\
\text { temporal }\end{array}$ & 1 & 11 & $\begin{array}{l}\text { Right hippocampal body; } \\
\text { Right hippocampal head }\end{array}$ & $\begin{array}{l}9.1(\mathrm{HCB}) \\
8.0(\mathrm{HCH})\end{array}$ & $\sqrt{+}$ \\
\hline 16 & $35 \mathrm{~F}$ & $\begin{array}{l}\text { Mesial temporal } \\
\text { (Bilateral hippocampus) }\end{array}$ & FIA & Left mesial temporal & 1 & 5 & Left hippocampal head & 8.0 & $\sqrt{+}$ \\
\hline 17 & $40 \mathrm{M}$ & $\begin{array}{l}\text { Mesial temporal } \\
\text { (Left hippocampus) }\end{array}$ & FIA & Left mesial parietal & 1 & 2 & - & - & $\sqrt{-}$ \\
\hline 18 & $39 \mathrm{M}$ & $\begin{array}{l}\text { Frontal } \\
\text { (Right mesial cingulate) }\end{array}$ & $\begin{array}{l}\text { FIA; } \\
\text { FTBTC }\end{array}$ & $\begin{array}{l}\text { Right mesial temporal } \\
\text { and left orbitofrontal } \\
\text { ( } 2 \text { types) }\end{array}$ & 2 & {$[8,4]$} & - & - & $\sqrt{-}$ \\
\hline 19 & $30 \mathrm{M}$ & $\begin{array}{l}\text { Frontal } \\
\text { (Right mesial cingulate) }\end{array}$ & $\mathrm{FA} ; \mathrm{FIA}$ & $\begin{array}{l}\text { Left mesial temporal } \\
\text { and left insula }\end{array}$ & 2 & {$[1,1]$} & - & - & $\sqrt{-}$ \\
\hline 20 & $23 \mathrm{~F}$ & $\begin{array}{l}\text { Mesial temporal } \\
\text { (Right hippocampus) }\end{array}$ & FIA & $\begin{array}{l}\text { Right posterior } \\
\text { temporal }\end{array}$ & 1 & 3 & - & - & $\sqrt{-}$ \\
\hline 21 & $35 \mathrm{M}$ & $\begin{array}{l}\text { Mesial temporal } \\
\text { (Bilateral hippocampus) }\end{array}$ & FA & $\begin{array}{l}\text { Right insula and } \\
\text { somatosensory cortex }\end{array}$ & 3 & {$[7,8,7]$} & Right hippocampal head & $\begin{array}{l}\text { Sub- } \\
\text { threshold }\end{array}$ & $\begin{array}{c}\text { Spread } \\
/ X_{+}\end{array}$ \\
\hline 22 & $44 \mathrm{~F}$ & $\begin{array}{l}\text { Frontal } \\
\text { (Right anterior cingulate) }\end{array}$ & FTBTC & Left cingulate & 1 & 1 & $\begin{array}{l}\text { Right anterior/mid- } \\
\text { cingulate }\end{array}$ & 15.2 & Spread \\
\hline 23 & $51 \mathrm{~F}$ & $\begin{array}{l}\text { Frontal } \\
\text { (Left anterior cingulate) }\end{array}$ & FIA & Left mesial temporal & 1 & 4 & Left anterior cingulate & 12.6 & Spread \\
\hline 24 & $20 M$ & $\begin{array}{l}\text { Frontal } \\
\text { (Left anterior cingulate) }\end{array}$ & FIA & $\begin{array}{l}\text { Left posterior } \\
\text { temporal }\end{array}$ & 1 & 1 & - & - & $\checkmark-$ \\
\hline 25 & $30 \mathrm{~F}$ & $\begin{array}{l}\text { Frontal } \\
\text { (Right anterior cingulate) }\end{array}$ & FIA & Left mesial temporal & 1 & 1 & - & - & $\sqrt{-}$ \\
\hline 26 & $20 \mathrm{M}$ & $\begin{array}{l}\text { Mesial temporal } \\
\text { (Right hippocampus) }\end{array}$ & FIA & Right mesial temporal & 2 & {$[1,2]$} & Right hippocampal body & 10.4 & $\checkmark+$ \\
\hline 27 & $32 \mathrm{M}$ & $\begin{array}{l}\text { Mesial temporal } \\
\text { (Bilateral hippocampus) }\end{array}$ & FIA & $\begin{array}{l}\text { Bilateral mesial } \\
\text { temporal }\end{array}$ & 3 & {$[4,3,3]$} & Hippocampal body & 9.8 & $\sqrt{+}$ \\
\hline
\end{tabular}

654 Table 2. Demographics and results for patients implanted with Behnke-Fried arrays

655 Individual patient demographics for stereo-EEG/Behnke-Fried array cases, including the number

656 of isolated single units found for each seizure in each patient, implant locations that showed 
657 significant waveshape alterations, the delay until waveforms surpassed $>1$ SD beyond the 658 preictal mean, and whether clinical observations matched these findings. FTBTC: focal to 659 bilateral tonic-clonic; FA: focal aware; FIA: focal with impaired awareness; HC: hippocampus;

660 MC: mid-cingulate; "Spread": matches clinical observations of seizure spread; $\sqrt{ }+:$ true positive

661 match for clinical observations; $\boldsymbol{V}$-: true negative match for clinical observations; $X+$ : false 662 positive match for clinical observations.

663 
bioRxiv preprint doi: https://doi.org/10.1101/2020.01.11.902817; this version posted January 19, 2020. The copyright holder for this preprint (which was not certified by peer review) is the author/funder. All rights reserved. No reuse allowed without permission.

NEURONAL ACTIVITY IN HUMAN SEIZURES

\begin{tabular}{|c|c|c|c|c|c|c|c|c|c|}
\hline \multirow{2}{*}{$\frac{\text { Patient }}{1}$} & \multirow{2}{*}{$\begin{array}{r}\text { Seizure \# } \\
1\end{array}$} & \multirow{2}{*}{$\frac{\text { Recruited? }}{X}$} & \multirow{2}{*}{$\begin{array}{l}\text { Units } \\
\text { from } \\
\text { convex } \\
\text { hull [n] } \\
52\end{array}$} & \multicolumn{2}{|c|}{$\begin{array}{l}\text { Units showing FR } \\
\text { increase } \\
\text { in ictal wavefront [n } \\
(\%)]\end{array}$} & \multicolumn{2}{|c|}{$\begin{array}{c}\text { Units showing } \\
\text { significant } \\
\text { FWHM increase [n (\%)] }\end{array}$} & \multicolumn{2}{|c|}{$\begin{array}{c}\text { Units showing } \\
\text { significant } \\
\text { amplitude decrease [n } \\
(\%)]\end{array}$} \\
\hline & & & & & $/ A$ & 2 & (4\%) & 3 & (6\%) \\
\hline \multirow[t]{2}{*}{2} & 1 & $x$ & 55 & & $/ A$ & 9 & $(16 \%)$ & 8 & $(15 \%)$ \\
\hline & 2 & $x$ & 49 & & $/ A$ & 3 & (6\%) & 2 & (4\%) \\
\hline \multirow[t]{3}{*}{3} & 1 & $\checkmark$ & 80 & 77 & (96\%) & 63 & (79\%) & 20 & $(25 \%)$ \\
\hline & 2 & $\checkmark$ & 80 & 70 & (88\%) & 68 & (85\%) & 38 & $(48 \%)$ \\
\hline & 3 & $\checkmark$ & 79 & 67 & (85\%) & 66 & $(84 \%)$ & 40 & (51\%) \\
\hline 4 & 1 & $\checkmark$ & 101 & 77 & (76\%) & 93 & (92\%) & 45 & $(45 \%)$ \\
\hline \multirow[t]{2}{*}{5} & 1 & $\checkmark$ & 117 & 82 & (70\%) & 114 & (97\%) & 103 & (88\%) \\
\hline & 2 & $\checkmark$ & 104 & 73 & (70\%) & 85 & (82\%) & 63 & (61\%) \\
\hline 6 & 1 & $x$ & 221 & & $/ A$ & 105 & $(48 \%)$ & 86 & (39\%) \\
\hline
\end{tabular}

\section{Table 3. Single unit data from Utah array population analyses}

665 Total number of units found in each patient and seizure for population analyses in Utah array

666 cases via the convex hull template-matching method, along with the number of units showing

667 significant increases in firing rate, spike full-width-at-half-maximum (FWHM), and decreases in

668 amplitude during the seizure. 


\section{VIDEO LEGENDS}

\section{Video 1. Location specific waveform changes during a spontaneous human seizure}

672 Local field potential (top) and spike amplitudes for three units in three different locations

673 (middle; red, blue and purple), with associated spike waveforms shown to the right. Shading

674 shows the mean $\pm 2 \mathrm{SD}$ for these units' preictal spike amplitudes. The locations of the BF

675 microwires that recorded these units are shown below, with colors maintained. Note the three

676 activity patterns: cessation of firing at seizure onset in the anterior temporal lobe (blue), stability

677 followed by loss of spike amplitude in the anterior cingulate (red), and stability throughout in the

678 mid-cingulate (purple).

\section{Video 2. Single unit waveform alterations in an ictal Behnke-Fried recording}

680 Single units undergo waveshape changes upon recruitment to the seizure, shown in real-time.

681 Upper trace: MUA bandpassed signal (300 Hz to $5 \mathrm{kHz}$; white), with current time shown in red,

682 earliest electrographic ictal activity in the patient occurs at dashed magenta line, with local

683 recruitment occurring at blue dashed line. Lower panels: shaded regions show mean $\pm 2 \mathrm{SD}$ for

684 preictal single units in red and blue, and lower amplitude multiunit activity in yellow (left).

685 Waveforms are displayed in real-time, with colors matching their assigned unit, and color

686 saturation showing the probability of a true match to that unit. The first two principal component

687 scores for these waveforms are shown on the right, with colors maintained. Note the stability of

688 waveforms prior to local recruitment, including after seizure onset, followed by marked loss of

689 amplitude at the moment of recruitment with associated tonic firing. 